\title{
Richtlijn simulatie teamtraining
}

\author{
C.R.M.G. Fluit,T.P.F.M. Klaassen
}

\section{Voorwoord}

De opdracht tot het ontwerpen van een In VIVO Richtlijn simulatie teamtraining is verleend aan de In VIVO kernteams van Nijmegen. De Richtlijn is ontworpen door een kleine projectgroep, bestaande uit drs. Lia Fluit en drs. Tim Klaassen (UMC St Radboud) met medewerking, in het bijzonder voor het literatuuronderzoek, van Laura Spinnewijn en Els Pelgrim (UMC St Radboud), van de werkgroep Skills en Simulatie van het UMC St Radboud en van de groep 'Klinische Instructie Door Simulatie' (KIDS-groep). De tekst is vervolgens becommentarieerd door het In VIVO kernteam van de Onderwijs- en Opleidingsregio (OOR) Nijmegen, door de 'Werkgroep Inhoudelijke Zaken Simulatie' (WIZS-groep) en door de KIDS-groep.

De projectgroep heeft zich voor het opstellen van deze Richtlijn gebaseerd op 1) de nationale en internationale literatuur, 2) een inventarisatie van bestaande toepassingen van de simulatie teamtraining in Nederland en 3) eigen ervaringen en gesprekken met betrokkenen bij de simulatie teamtraining in het UMC St Radboud Nijmegen.

\section{Status van de Richtlijn}

Deze Richtlijn is bedoeld als een hulpmiddel bij het omgaan met simulatie teamtraining, en is zoveel mogelijk gebaseerd op argumentatie uit de literatuur en de praktijk. Omdat in Nederland de simulatie teamtraining pas enkele jaren gebruikelijk is, is het noodzakelijk de Richtlijn in de toekomst verder te blijven ontwikkelen.
Er is een wisselwerking tussen de status van deze Richtlijn en de modernisering in de vervolgopleidingen. Enerzijds beoogt de Richtlijn hulp te bieden bij de vernieuwing van de opleidingen, anderzijds is zij mede gebaseerd op recente ervaringen die zijn opgedaan met de discussies over de nieuwe curricula voor de opleidingen. Wij beschouwen daarom ook de modernisering van de opleidingen als een dynamisch proces dat niet 'af' is bij de vaststelling van de nieuwe curricula. Deze Richtlijn beoogt de verdere ontwikkeling en verfijning van simulatie teamtraining in de toekomst te faciliteren.

Het eerste deel is de feitelijke Richtlijn; het tweede deel van dit document vormt de verantwoording. Het format is ontleend aan de standaarden van het Nederlands Huisartsen Genootschap (NHG)

\section{Definitie, doel en functie van simulatie teamtraining}

Simulatie teamtraining binnen de gezondheidszorg is een vorm van training waarbij, door middel van simulatie, medische competenties én competenties op het gebied van samenwerking, communicatie, organisatie en leiderschap worden geoefend. De situaties die getraind worden kunnen zeer divers zijn. Veelal betreft het acute situaties, waarin in een team gewerkt wordt, er snel en doelmatig gehandeld moet worden en er sprake is van een zekere mate van stress. Een team wordt in deze Richtlijn gedefinieerd als een groep van twee of meer individuen, die samenwerken om een gemeenschappelijk doel te realiseren. 
Het trainen van competenties in zulke gesimuleerde situaties draagt ertoe bij dat fouten in de zorg kunnen worden voorkomen. Dit komt de kwaliteit van zorg en patiëntveiligheid ten goede. Verder kent dit simulatieonderwijs voor de professional zelf ook verschillende voordelen. Simulatie biedt namelijk een leeromgeving waarin nog fouten gemaakt kúnnen en mógen worden en daardoor van deze fouten in een veilige omgeving geleerd kan worden.

\section{Te beoordelen competenties \\ Technische en niet-technische vaardigheden}

Er wordt onderscheid gemaakt tussen technische en niet-technische vaardigheden. Onder technische vaardigheden worden alle medische handelingen verstaan. Onder niet-technische vaardigheden vallen teamcompetenties: interpersoonlijke vaardigheden als communicatie, samenwerking en leiderschap en cognitieve vaardigheden als omgevingsbewustzijn en beslisvaardigheid. In een teamtraining kunnen zowel technische als niet-technische vaardigheden aan bod komen.

\section{Teamcompetenties}

Aan te bevelen is de Ottawa Global Rating Scale $^{1}$ waarbij de volgende teamcompetenties aan bod komen:

- Problem solving

- Situational awareness

- Resource utilization

- Leadership

- Communication

Andere indelingen zijn de zogenaamde Anaesthetists' Non-Technical Skills (ANTS) ${ }^{2}$ en de Non-Technical Skills for Surgeons (NOTSS). ${ }^{3}$ In een simulatie teamtraining moet in ieder geval aandacht zijn voor één of meerdere van de vijf genoemde competenties.
Als hulpmiddel om de communicatie tussen verschillende hulpverleners adequaat en helder te laten verlopen is het SBAR-instrument ontwikkeld, wat staat voor Situation, Background, Assessment \& Recommendation. ${ }^{4}$ Als controlehulpmiddel kan de Time-out procedure worden gebruikt. Voordat er tot actie wordt overgegaan, bijvoorbeeld in een operatiekamer, wordt er met alle teamleden een aantal zaken geverifieerd, zoals het te maken hebben met de juiste patiënt, het hanteren van de juiste instrumenten en het volgen van de juiste procedure.

\section{Relatie met de CanMEDS}

Met behulp van simulatieonderwijs kunnen meerdere CanMEDS competenties worden geoefend, zoals medisch handelen bij de technische vaardigheden, maar ook communicatie, organisatie, samenwerking en professionaliteit bij de niet-technische vaardigheden. ${ }^{5-6}$ Het unieke van deze simulatie teamtrainingen is dat deze vaardigheden getraind worden in een multidisciplinair team, iets waar tot op heden in de medische vervolgopleidingen weinig aandacht aan is besteed.

\section{Competenties van de instructeur(s)}

Het is belangrijk dat instructeurs:

- inhoudelijk deskundig zijn,

- deskundig zijn op het gebied van niettechnische vaardigheden cq teamcompetenties,

- ervaren, geschoolde docenten zijn,

- vaardig zijn in het omgaan met simulatoren en met het manipuleren van het scenario,

- in staat zijn op constructieve wijze feedback te geven.

Bij voorkeur zijn er twee instructeurs aanwezig bij de simulatie, waarvan ten minste één instructeur deskundig is op het gebied van de inhoud. Het grote voordeel 
van twee instructeurs is dat op het moment dat één zich bezighoudt met het laten draaien van het scenario, de ander gericht kan observeren aan de hand van de leerdoelstellingen van dit specifieke scenario. Bovendien kunnen de instructeurs elkaar aanvullen en ondersteunen bij de debriefing.

\section{Het ontwerpen van een simulatie teamtraining Oriëntatiefase}

In deze fase moet worden vastgesteld: ${ }^{7}$

- wat de uitgangspositie van de teamleden is (in welke spoedeisende situatie voelt men zich onveilig of onzeker?),

- welke procedures en richtlijnen omgezet kunnen worden in checklisten,

- of er checklisten aanwezig zijn om apparatuur te controleren op functionaliteit, compleetheid en onderhoudstatus,

- of taken en bevoegdheden zijn vastgesteld en vastgelegd (wie doet wat, wanneer en wie is eindverantwoordelijk?),

- of alle teamleden zijn geschoold in de ABC-methodiek (Airway/Breathing/Circulation),

- welke acute situaties eerste aandacht behoeven,

- welke middelen er beschikbaar zijn (ruimte, materialen en financiële middelen).

Simulatie teamtraining gebeurt op basis van een team/taakanalyse, een 'needs assessment' en/of een knelpuntenanalyse. Vooraf wordt bepaald welke competenties geoefend kunnen worden. De kennis, vaardigheden en attitudes die nodig zijn om taken goed uit te voeren worden hiervan afgeleid. Zo kunnen per scenario leerdoelen worden geformuleerd. De simulatie zelf kan ook aanleiding zijn om leerdoelen te formuleren.

\section{Ontwikkelfase}

Hieronder vallen de volgende stappen: ${ }^{7}$

- maak een projectplan voor de simulatietraining,

- redigeer protocollen en richtlijnen tot checklisten,

- maak checklisten om apparatuur en middelen te controleren vóór aanvang van elke dienst,

- ontwerp scenario's betreffende de spoedeisende situaties die gesimuleerd gaan worden,

- vul het scenario aan met een instructeurshandleiding en instructie voor de teamleden,

- school teamleden indien nodig in de ABC-methodiek,

- betrek één van de teamleden in deze fase om draagvlak te creëren en om praktische adviezen in te winnen.

In de theoretische verantwoording van deze Richtlijn (het tweede deel) staat een stappenplan voor het ontwerpen van een set gelijkwaardige scenario's (Tabel 3). In Bijlage 2 staan voorbeelden die laten zien dat verschillende elementen uit een scenario kunnen leiden tot verschillende aandachtspunten in de nabespreking. Bijlage 3 bevat een voorbeeld van een scenario.

\section{Vormgeving van een simulatie teamtraining}

Bij het opzetten van een simulatie teamtraining is het belangrijk na te gaan welke middelen beschikbaar zijn en aan welke voorwaarden voldaan kan worden om de training vorm te geven, zoals:

- simulatiepatiënt of simulatiepop,

- eigen werkplek of een simulatiecentrum,

- frequentie (is er een mogelijkheid om herhaald te trainen of is het éénmalig?),

- duur (kunnen deelnemers een dagdeel worden vrij geroosterd of is de trainingstijd beperkt?), 
- samenstelling team (kunnen meerdere disciplines deelnemen aan de training?),

- mogelijkheid van het op video opnemen van de simulatie teamtraining,

- de aanwezigheid van een aparte debriefing ruimte.

Een simulatie teamtraining met een multidisciplinair team waarbij de simulatie teamtraining wordt opgenomen (de zogenaamde Video-Assisted Realtime Simulation [VARS] training) heeft de voorkeur maar zal niet altijd haalbaar zijn. Bij een VARS training zijn de volgende voorwaarden van belang:

- de participanten en instructeurs zijn een dagdeel vrij geroosterd voor de training,

- het team dat getraind wordt bestaat uit meerdere personen van verschillende disciplines (bijvoorbeeld verpleegkundigen, verloskundigen, fysiotherapeuten, artsen in opleiding tot specialist [aios], stafleden), afhankelijk van het scenario en doelstellingen,

- men heeft de beschikking over een simulatieomgeving die de echte werkomgeving in realiteitsgehalte benadert,

- het uit te voeren scenario wordt gefilmd,

- er is bij voorkeur een aparte debriefing ruimte, waar het scenario aan de hand van getoonde videobeelden direct na het doorlopen van een scenario met de participanten kan worden nabesproken.

\section{Uitvoering van een simulatie teamtraining}

Een simulatie teamtraining kan, analoog aan de indeling die binnen ATLS en
APLS* wordt gebruikt, worden opgeknipt in drie delen: set, dialogue en closure. Aan het eind van ieder deel wordt aangegeven welke aspecten voor de VARS training belangrijk zijn.

De set

De set bestaat uit zowel de voorbereiding voorafgaand aan de simulatie, als de introductie van de simulatie zelf.

\section{Activiteiten, voorafgaand aan de} simulatiesessie:

- zorg dat het instructeursteam volledig bekend is met het materiaal en het scenario,

- zorg dat het instructeursteam er de hele tijd bij kan zijn, inclusief de nabespreking,

- om het zo echt mogelijk te laten zijn is het gebruik van echte aanvraagformulieren, uitslagformulieren, foto's, materialen aan te bevelen.

- check ALLE materialen en benodigdheden op aanwezigheid én check of ze werken. Het beste is om echt te testen of alles naar behoren werkt,

- stel je op de hoogte van de achtergronden van deelnemers van de training, bijvoorbeeld aan de hand van een vragenlijst met vragen over voorgaande ervaringen, gevolgde scholing etc.,

- zorg dat de deelnemers zo goed mogelijk voorbereid naar een simulatietraining komen, bijvoorbeeld door een theoretische voorbereiding en zo nodig een pretest.

\section{De start van de simulatie:}

- begin de simulatie met een introductie van de simulatie, leg uit hoe gegevens

\footnotetext{
* Advanced Trauma Life Support (ATLS) en Advanced Pediatric Life Support (APLS); zie ook www.atls.nl en
} www.aplsonline.com. 
verkregen kunnen worden, hoe de apparatuur werkt etc. Geef het te trainen team tijd om vertrouwd te raken met de simulatiesetting

- leg uit hoe de hele simulatie verloopt,

- benadruk dat alles wat in de simulatie gebeurt en wordt gezegd binnen het team blijft en dus vertrouwelijk is. Het is niet de bedoeling dat men over het handelen van collega's praat buiten de simulatiesessie! Hiertoe ondertekenen deelnemers een verklaring tot geheimhouding,

- maak alle rollen duidelijk,

- relateer aan het grotere geheel (de plaats in het curriculum),

- geef het doel aan van de simulatie, koppel de simulatie aan (persoonlijke) leerdoelen,

- stel het team op zijn gemak,

- geef de informatie over de casus,

- controleer of het team alles heeft begrepen, bijvoorbeeld door het laten herhalen van de instructie.

\section{Aanvullende punten bij een VARS training:}

- geef aan dat de simulatie wordt opgenomen en dat deze gezamenlijk wordt bekeken na afloop,

- geef leden van het team die geen actieve rol hebben in de simulatie een observatieopdracht, bijvoorbeeld het specifiek observeren van bepaalde competenties (zoals het observeren van de manier waarop leiding wordt gegeven in dit team).

\section{Dialogue}

De dialogue kan worden verdeeld in het doorlopen van het scenario en de nabespreking (debriefing).

Het scenario: het doorlopen van een scenario gebeurt real-time. In principe hoeft de instructeur niet dicht bij het team te zijn. Specifieke taken van de instruc- teur(s) tijdens het doorlopen van het scenario:

- observeer het team en individuele teamleden tijdens het scenario (hoe voeren zij de taken uit?),

- houd de leerdoelen in gedachten en koppel geobserveerd gedrag aan gewenst gedrag,

- noteer je observaties, schrijf op wat je ziet, wees voorzichtig met te snelle conclusies,

- gebruik hierbij een formulier waarop je gemakkelijk tijd en waarneming (eventueel per competentie) kan noteren,

- geef zonodig de gevraagde informatie en/of bedien apparatuur waar dat nodig,

- bewaak de tijd! Stop het scenario op het juiste moment.

\section{Aanvullende punten bij een VARS training:}

- laat teamleden die niet aan bod komen in het scenario, in de debriefingruimte kijken naar het verloop van het scenario,

- registreer momenten die men in de nabespreking aan de orde wil stellen. Markeer deze in de tijdsbalk van de video-opname.

De debriefing (nabespreking): de nabespreking vindt in een ruimte plaats waar iedereen kan zitten. Het beste is om hiervoor een aparte ruimte in te richten. Bespreek direct na de simulatie kort met de mede-instructeurs welke leerpunten met dit team besproken moeten worden. Neem hier één tot twee minuten tijd voor terwijl de deelnemers kunnen ontladen, iets te drinken kunnen pakken, naar het toilet kunnen etc.

Een goede nabespreking bevat de volgende elementen:

- een stimulerende en veilige leeromgeving,

- aandacht voor goede en verbeterpunten,

- focus op de belangrijkste leerpunten, 
- bespreking van teamcompetenties,

- aandacht voor beschrijving - analyse toepassing.

Voor de eerste nabesprekingsessie geldt: geef aan hoe de nabespreking zal plaatsvinden; laat het team eerst even 'stoom afblazen', geef deelnemers ruimte om te vertellen hoe ze zich voelen na de simulatie.

Een veel toegepast model voor de nabespreking is het onderscheid in drie fasen:

- Beschrijvende fase: deelnemers geven hun perceptie van wat er is gebeurd. Vooral van belang zijn leermomenten zoals: waar is afgeweken van protocollen, waar begrepen ze niet meer wat er gebeurde, waneer durfden ze niet hardop te zeggen wat er aan de hand was.

- Analysefase: de instructeur helpt deelnemers beter te begrijpen waarom er op een bepaalde manier gehandeld is, in positieve en negatieve zin. Er worden vragen gesteld, uitleg (aan elkaar) gegeven, gediscussieerd etc.

- Toepassingsfase: het formuleren van de voornemens voor de praktijk; wat zijn leerpunten geweest voor individu en team?

Het verloop van de debriefing:

- selecteer bij het begin een situatie waar deelnemers de juiste kennis, vaardigheden en/of attituden lieten zien. Dit bekrachtigt goed handelen en zorgt dat participanten meer openstaan voor kritische feedback. Baseer de feedback hierbij op concrete observaties,

- benoem situaties waar deelnemers minder gepaste kennis, vaardigheden en/of attituden lieten zien. Identificeer, analyseer en onderzoek mogelijke andere oplossingen dan de getoonde handelwijze. Eventueel kunnen specifieke sterkten en zwakten van individuele deelnemers worden benoemd. Ook hier geldt: ba- seer de feedback hierbij op concrete observaties,

- laat eerst de deelnemers zelf commentaar geven, voordat de instructeurs aan het woord komen. Zo wordt vermeden dat enkel instructeurs aan het woord zijn,

- laat de deelnemers reflecteren op hun eigen handelen, zorg daarbij dat ook positieve punten worden genoemd,

- laat deelnemers hun ervaringen tijdens de simulatie generaliseren naar ervaringen in de praktijk en laat formuleren hoe zij dit in de praktijk ook zouden doen, of anders zouden doen. Wanneer deelnemers zelf met oplossingen komen, zullen zij deze eerder in de praktijk omzetten dan wanneer de instructeur oplossingen aandraagt,

- koppel de leerpunten aan de leerdoelen en competenties,

- houd het aantal leerpunten beperkt (één à twee per individu),

- wees je als instructeur bewust van het gegeven dat het in de praktijk vaak lastig blijkt te zijn om aan directe collega's feedback te geven,

- voorkom veroordelend taalgebruik (blijf als instructeur objectief in het geven van feedback).

Praktische tips:

- bewaak de tijd zorgvuldig: zorg voor voldoende tijd om alle onderdelen in de nabespreking aan bod te laten komen. In de regel duurt de nabespreking twee tot drie maal zo lang als het doorlopen van een scenario zelf,

- praat nooit wanneer de video nog loopt,

- luister goed naar de deelnemers; toon interesse,

- let tijdens de nabespreking op dat iedereen aan het woord komt (dit kan door middel van een vooraf besproken observatietaak aan de teamleden die geen actieve rol in het scenario hadden), 
- stel vragen die het leerproces en reflecteren op gang brengen. Bijlage 4 geeft een overzicht van vragen die bij de nabespreking gebruikt kunnen worden. Het stellen van open vragen, waar geen 'ja' of 'nee' op geantwoord kan worden (hoe, waarom, wanneer, wie), zet aan tot het kritisch naar zichzelf kijken en levert uiteindelijk meer informatie op dan het stellen van gesloten vragen (zie het tweede deel; de debriefing). Dat komt het leerproces ten goede.

\section{Aanvullende punten bij een VARS training:}

- als de simulatie teamtraining wordt opgenomen, leg dan uit dat de opname gedeeltelijk zal worden bekeken (beter een paar zaken goed, dan veel zaken half bespreken) en dat zowel teamleden als instructeur de band kunnen onderbreken om iets te bespreken,

- wat betreft de rol van de video: het laten zien van goede voorbeelden, de discussie richting geven, goede en slechte aspecten van het handelen beter visualiseren,

- realiseer je dat het meestal niet mogelijk is om de hele video terug te zien. Maak dus keuzes in wat wel en niet te bespreken met dit team.

\section{Closure}

Belangrijke aandachtspunten bij het bespreken van de leerpunten en bij de afsluiting van de simulatiesessie:

- geef gelegenheid om resterende vragen te stellen,

- kom terug op leerdoelen,

- check wat de deelnemers hebben geleerd. Dit kan heel goed door ze zelf te laten verwoorden wat ze nu van deze sessie hebben geleerd (bijvoorbeeld één goed punt en één verbeterpunt),

- leg relatie met praktijk, laat teamleden voornemens voor de praktijk formuleren of maak een concreet plan voor het werk in de klinische praktijk,
- vat samen/formuleer een 'take home message'.

\section{Beoordeling}

Het beoordelen van teamprestaties kan aan de hand van een observatieformulier. De beoordeling zal met name formatief van aard zijn en dient dan ook als leidraad voor het geven van de feedback in de debriefing fase. In Bijlage 5 is een voorbeeld van een evaluatieformulier opgenomen dat gebruikt kan worden om teams te beoordelen op de diverse teamcompetenties.

Het evalueren van de effecten van een teamtraining is niet eenvoudig. Toch is het belangrijk deze evaluatie uit te voeren, niet in de laatste plaats omdat een evaluatie punten op kan leveren die gebruikt kunnen worden voor verbetering van de eigen trainingen.

In het tweede deel zijn verschillende instrumenten beschreven om evaluaties uit te voeren. De meeste instrumenten meten echter niet de effectiviteit van trainingen, oftewel in hoeverre het handelen in de praktijk wordt beïnvloed, maar meten reacties en eerste leereffecten.

\section{De plaats van de simulatie teamtraining in de opleiding}

Idealiter wordt de simulatie teamtraining ingebouwd in curricula van medische (vervolg-)opleidingen en in bij- en nascholingsprogramma's en vormt het een onderdeel van een leerketen.

Het ontwerpen van een dergelijk curriculum kan op de volgende wijze gefaseerd worden:

- voer een knelpuntenanalyse uit,

- bepaal welke knelpunten middels onderwijs opgelost kunnen worden,

- definieer de leerinhouden op basis van geïdentificeerde knelpunten,

- selecteer de onderwijsmethode, 
- bepaal een tijdspad; wanneer wordt welke vorm van onderwijs ingezet (sequencing events),

- controleer de implementatie,

- evalueer (formatief/summatief).

Verdere suggesties voor het inplannen van simulatie teamtraining:

- ga na waar simulatie teamtraining kan aansluiten op eventuele bestaande programma's,

- koppel simulatieonderwijs aan onderwijsprogramma's die gericht zijn op patiëntveiligheid; zo wordt acceptatie en haalbaarheid van implementatie vergroot,
- neem situaties die veel voorkomen in de praktijk waarbij snel fouten gemaakt kunnen worden (complex, stressvol etc.),

- neem situaties die niet vaak voorkomen, maar wanneer ze voorkomen helemaal goed moeten gaan,

- maak gebruik van eerdere ervaringen met simulatietrainingen, van ervaringen van deelnemers en kijk naar behoeften vanuit de organisatie zelf,

- raadpleeg regelmatig wetenschappelijke literatuur en voorhanden zijnde richtlijnen en curricula (zie voor meer informatie ook de theoretische verantwoording van deze Richtlijn). 